\title{
Self-Exploration on Anxiety in Chakra Meditation Experienced People - The Mediation Effect of Emotional Health state Perception
}

\author{
Sela $\operatorname{Lim}^{1}$ and HeeJung Lee ${ }^{2 *}$ \\ ${ }^{1}$ Department of Clinical Psychology, NungIn University, Paltan-myeon, Hwaseong-si, \\ Gyeonggi-do, Repulic of Korea, \\ ${ }^{2}$ Department of Naturopathic, Dongbang Culture University, Seongbuk-gu, Seoul, \\ Repulic of Korea \\ ${ }^{1}$ sera325@nate.com, ${ }^{2 a n a h j i l e e 57 @ n a v e r . c o m ~}$
}

\begin{abstract}
This study explored correlation of People of $S$ city's for chakra meditation experience motivation, and Anxiety to confirm mediation model and path of physical and emotional and social state perception. To this end, data was collected from 223 survey results conducted by 250. The survey consisted of, the Chakra Meditation Experience Motivation scale, the Mental Health (SCL90-R) Questionnaire for Anxiety and The Korean Health Status Measure. The results were analyzed by SPSS macro program. To verify average and standard deviation of variables and mediation model of how chakra meditation experience motivation to mental health through, health state Perception the author used bootstrapping methods. For the research result, this study presented descriptive statics for each variable of respondents' and conducted correlation analysis among Chakra meditation experience motivation(selfexploration) to Anxiety through emotional health state perception (B=0.821, CI: [0.123 1.788]). However, the path model on the relationship among Chakra meditation experience motivation(self-exploration) and emotional health state perception and Anxiety was verified and suggested as well.
\end{abstract}

Keywords: Chakra meditation experienced people, Chakra meditation experience motivation, Mental health, Health state perception, Mediation effect

\section{Introduction}

Recently, more and more people are complaining of mental and physical pain caused by anxiety. As the belief that psychological stability can be pursued through self-exploration spreads, the movement to restore their state of health perception through chakra meditation is active. This method is attributed to the fact that self-perceived physical, emotional and social health perception conditions are related to mental health. In particular, through chakra meditation, one seeks health by dealing with the anxiety that is a key factor of mental health through self-exploration [1]. Chakra meditation has traditionally originated from the practice of straightening the spine, sitting upright in a standing position, and focusing the mind on parts of the body. A wide range of meditation methods, all with an empirical, traditional back ground, are currently in use many of the world's societies [2][3]. Such methods are used for coping with life events or simply for a conscious optimization of personal and physical health [3][4]. As these methods become better researched, some are being widely accepted in health

Article history:

Received (December 1, 2019), Review Result (January 11, 2020), Accepted (February 15, 2020) 
care systems [5]. In Sanskrit, chakra means whirlpool or wheel, which means that the energy in the body emits and contains energy as the wheel rotates along with the cosmic energy. In other words, chakra meditation experiences are known to be effective in keeping the mind healthy and to balance the physical, mental, cognitive and spiritual realms [6].

Above all, positive perceptions of physical, social and emotional health are factors influencing anxiety reduction [7]. Therefore, maintaining healthy mental function requires efforts and management to maintain the change of mind with an emphasis on behavior [8]. It has been reported that the goal of mental health through the activation of these chakra stimuli for physical, social and emotional aspects of health [7]. Chakra activation is not only meditation but also physical exercise through yoga. Physical exercise therapy has been reported to improve Anxiety by improving positive mental health and reducing negative mental health. Chakra disharmony is a factor leading to physical illness and emotional problems. Awakening or activating chakras to restore the balance of mind and body can help maintain or produce not only the mind but also the physical health, and in particular, the elements that are in harmony with the soul.

Chakra meditation, which is the preferred means of arousing chakras, can develop the potential to grow physically and mentally by applying yoga meditation practices to activate each chakra. Meditative chakra in yoga has a positive effect on the physical and mental aspects through various positions and breathing. And it helps to get positive thinking and affects mental health.

According to Seong-ho Kim's [9] research, chakra meditation was effective in reducing negative thoughts and stress responses caused by stress and physical symptoms. Sung-sook Do [6] claimed that participating in chakra meditation programs was beneficial to mental health. Young-gun Song [6] argued that chakra activation affects Anxiety. Na-young Kim [7] argued that mental and physical health is very closely related.

These results report that the problems of somatization, compulsion, interpersonal sensitivity, depression, anxiety, hostility, paranoia, and psychosis are at the basis of determining the mental health of human life. In particular, self-exploration through chakra activation is correlated with Anxiety [10][11][12] and mental health is correlated with physical health [13].

All study embrace a holistic health perspective-i.e. that human's function as integrated units and, consequently, changes at one point may have synergistic effects at another point, another level or even on the whole person. These observations suggest that regular practice of chakra meditation can bring significant improvement in the autonomic balance, respiratory performance and well-being. It also facilitates secretion of melatonin from the pineal gland, which may be acting as a psycho sensitive hormone. It is possible that if chakra meditation is administered along with routine army exercises, mental performance can be improved. [14] To detect holistic changes, it seems appropriate to use well-known health-related selfexploration and anxiety and emotional and social health conditions measures in Chakra meditation research. During the last decades, new training centers have been established where courses are held that are directed towards a holistic health approach to life.

The purpose of this study is to build a theoretical foundation based on the claim that the people who have experienced chakra yoga meditation, reported in previous domestic studies, have increased self-exploration and lead to mental health.

Although the results of preceding studies are being reported, most domestic and international studies on chakra report the results of the pre-and post-testing of programs through the activities of chakra on a small number of subjects, but did not analyze their 
experiences in detail. Moreover, most preceding studies did not conduct research on a large number of subjects.

While previous studies argued that chakra is a factor that effects mental health, they were limited in that they did not use standardized psychological measurement tools to examine mental health closely. Anxiety factors vary widely, but few studies have analyzed which are characteristic of chakra activity.

However, there is a lack of research that has been verified this in detail using assessment tools. Although there are claims that chakra meditation experiences alleviate physical and mental pain for people, few studies have measured this in detail.

The purpose of this study is to measure the motivational factors, physical, emotional, social health status and Anxiety factors of people who have experienced chakra meditation, and to explore the motives of meditation experience (benevolence, escape reality, self-exploration, self-love, emotional stability) and examine whether health status (physical, social, emotional) can be a mediator in the path from emotional stability to Anxiety factors.

\section{Methods}

\subsection{Subjects and data collection}

This study was conducted from August 2018 to September 2018, for those who participated in the chakra meditation program operation agency in Seoul of Korea. Finally, the data total of 223 participants was analyzed. [Table 1] Subjects for the study were selected from Zen center. Total of 223 participants were selected. Age of the Subjects was ranged from 40 to 79 years. All the subjects were divided randomly into 11 experimental group's i.e.

Table 1. General characteristics of subjects

\begin{tabular}{|c|c|c|c|c|}
\hline \multirow{2}{*}{\multicolumn{2}{|c|}{-}} & \multicolumn{2}{|c|}{ Subjects } & \multirow{2}{*}{$\%$} \\
\hline & & Male & Female & \\
\hline Ages & over the age of 40 & \multicolumn{2}{|c|}{23} & 10.31 \\
\hline & over the age of 50 & \multicolumn{2}{|c|}{77} & 34.53 \\
\hline & over the age of 60 & \multicolumn{2}{|c|}{87} & 39.01 \\
\hline & over the age of 70 & \multicolumn{2}{|c|}{29} & 13.00 \\
\hline & missing value & \multicolumn{2}{|c|}{7} & 3.14 \\
\hline \multicolumn{2}{|r|}{ Total } & \multicolumn{2}{|c|}{223} & 100.00 \\
\hline
\end{tabular}

\subsection{Method of chakra meditation: Asana and Pranayama and Cocentration at various Chakras}

We used the program for chakra meditation, which was developed by Devi, Chasauria \& Udupa and Lee [1][15].

Chakra meditation which is as follows: Thereafter, the therapist is advised to:

(1) Perform Asanas. Asanas for 5 times slowly and steadily. Asana is again repeated in the same way for 5 times in 15 seconds. Its position was just front banding and back banding among the Asanas.

(2) Perform Pranayama. The practitioner takes a deep expiration, closes one nostril with middle finger, takes a deep inspiration for 5 seconds, holds it for 20 seconds and runs out the 
air in 10 seconds. At the same ration, the practitioner repeats the performance, through the other nostril by closing the first one by the thumb alternately. Like this one carry on Pranayama for 5 times slowly and steadily. Takes his mind and fixes it at the Muladhara Chakra for three minutes. Similarly, takes up his mind to a circle around and inside the Swadhisthan Chakra for another three minutes.

(3) Taking the mind and allow it to concentrate at the Manipura Chakra for three minutes. After Anahata Chakra, takes the mind upwards and fix-up it for three minutes at the Vishudha Chakra. Takes up his (and her) mind to the Sahasrara Chakra (cerebral cortex) for three minutes. Perform Pranayama 5 times. This is followed by concentration on various Chakras meditation for a similar period on a reverse order. Pranayama is again repeated in the same way for 5 times. Lastly, the volunteer is asked to perform Savasana for three minutes, as mentioned above.

\subsection{Measures}

\subsubsection{Chakra meditation experience scale}

The questionnaire on meditation methods of subjects who experienced chakra meditation included the following: The psychological conflicts or problems to solve through meditation, and the helpful part in solving a psychological problem. Meditation motivation scale was developed by Ha [16][17] and modified by Kim [17]. A total of items is composed of 5 subfactors. Sub-factors consist of compassion, escapism, self-exploration, self love and emotional stability. The higher the total score, the higher the motivation for meditation. In this study, the total of Cronbach's $\alpha$ was .936 [Table 2].

Table 2. Reliability of chakra meditation experience motivation scale

\begin{tabular}{|l|l|l|}
\hline Sub scale & Item number & Cronbach's $\alpha$ \\
\hline compassion & $5,10,14,19,25$ & .798 \\
\hline escapism & $9,15,20,23$ & .795 \\
\hline self-exploration & $1,3,7,17,21$ & .800 \\
\hline self- love & $2,8,12,18,22$ & .838 \\
\hline emotional stability & $6,13,16$ & .761 \\
\hline Total & 25 item & .936 \\
\hline
\end{tabular}

\subsubsection{Anxiety: Symptom checklist-90-revision (SCL-90-R)}

In order to measure mental health, we used the Korean standardized version of Symptom Checklist-90-Revision (SCL-90-R) [18] which was developed by Derrogatis, Lipman \& Covi. [19] In the present study, the total of the Cronbach' s $\alpha$ was .856.

\subsubsection{State of health perception}

In order to measure physical and emotional and social health state, we used the State of Health Inventory (K-SHI), which was developed by Shin [20] which was developed by $\mathrm{Kim}[21]$. We refer to the questionnaire which is an analysis of the items and the factor analysis that are appropriate for Korean Chakra Meditation Experienced men and women. In the present study, the total of the Health State of Cronbach's $\alpha$ was .929 [Table 3]. 
Table 3. Reliability of health status measure

\begin{tabular}{|l|l|l|}
\hline Sub scale & Item number & Cronbach's $\alpha$ \\
\hline Physical health state & $\begin{array}{l}1,2,3,4,5,6,7,8,9,10,11, \\
12,13,14,15\end{array}$ & .872 \\
\hline Emotional health state & $16,17,18,19,20$ & .863 \\
\hline Social health state & $21,22,23,24$ & .840 \\
\hline Total & 25 item & .929 \\
\hline
\end{tabular}

\subsection{Data analysis}

The collected data were analyzed by SPSS 22.0 version (IBM Corp., Armonk, NY, USA). First, we conducted descriptive statistics to investigate the demographic characteristics of the subjects. Second, the reliability of each variable was tested fourth; Pearson's correlation analysis was used to examine the relationship between assumed factors. Third, regression analysis was used to examine the effects of self-exploration on anxiety.

\section{Results}

\subsection{Path model}

A state of health analysis was conducted to confirm the effects of self-exploration. Specifically, the self-exploration has a significant effect on the satisfaction of emotional health state $(\mathrm{B}=-.147, \mathrm{t}=-2.323, \mathrm{p}<.05)$, In addition, the physical health state and emotional health state was found to have a significant effect on Anxiety $(\mathrm{B}=-4.300, \mathrm{t}=-2.202, \mathrm{p}<.05)$ and $(\mathrm{B}=-5.594, \mathrm{t}=-4.235, \mathrm{p}<.001)$, and the self-exploration was found to have a significant effect Anxiety $(\mathrm{B}=1.931, \mathrm{t}=2.504, \mathrm{p}<.05)$.

\subsection{Measurement model}

We performed bootstrapping by extracting 2000 parts of the self-exploration of chakra meditation experience motivation to the Anxiety of mental health through the emotional health state of health state. As a result, the indirect effect was not significant because the path through the satisfaction of heterosexual satisfaction included 0 at $-.202 \sim .019$ in the $95 \%$ confidence interval of the indirect effect ( $\mathrm{B}=0.821$, CI:[0.123 1.788]).

\section{Conclusions}

For the results of this study, we examined the significant correlations between motivation for chakra meditation experience, Anxiety, and health condition among adults aged 40 to 70 . We also analyzed the mediating effects of health status on the path of chakra meditation motivation to Anxiety. Chakras also play a large role in the mental realm. Chakras contain the mental programming that governs self-exploration and anxiety. The significance of the results is as follows.

First, Hwang-ok and Sela [22] argued that self-exploration correlated with anxiety, and this research is consistent with this claim. In other words, those who have meditation experience have emotional stability by controlling anxiety through self-exploration. This 
suggests that self-exploration can be helpful for emotional stability and can help anxiety.

Second, Seong-ho Kim [9] argued that chakra activation can achieve a complete transformation of body and mind by eliminating negative thinking and respond positively to the mental stress responses. This study partially agrees with those results. This means that chakra activation affects the physical, emotional and cognitive domains.

In other words, chakra meditation experience affects the emotional health status and suggests that chakra meditation may be an effective way to alleviate mental health in adults who are exposed to anxiety caused by various stressors.

Third, Young-gun Song's [6] study claimed that chakra meditation experience has an effect on Anxiety. This study partially agrees with the results. This suggests that chakra yoga for meditation may help to alleviate anxiety among those who have experienced meditation.

In addition, in the study of physical fitness, Ji-young Choi and Kyung-hyun Seo [23] reported that meditative yoga mitigates stress response and perceived physical symptoms. Chakra meditation was associated with anxiety, as in Field [24]. This research is consistent with both of the above mentioned claims. Above all, this study suggests that chakra meditation experiences are related to Anxiety, consistent with Narthaniels [25], who found that chakra meditation experience helps positive thinking and helps mental health. In sum, self-exploration among the motives of meditation experience of chakra meditation experienced through the emotional state of health perception and reached the aspect of anxiety in the area of mental health. In the future research, the number of subjects who have experienced chakra meditation should be secured and the group should be further subdivided. The duration of the chakra meditation should be analyzed with clear criteria. It is also necessary to control the experience of chakra meditation through experimental design and to examine the effects of self-exploration on anxiety. Despite these limitations, this finding showed that was a difference in motivation for chakra meditation depending on the characteristics of the subjects who experienced chakra meditation. Furthermore, it is significant that self-exploration affect anxiety.

\section{References}

[1] J. S. Lee, “A feast of Zen meditation, Seoul,” NungIn Publishing Corp, (2015)

[2] K. Honda and J. S. Jacobson, "Use of complementary and alternative medicine among United States adults, The influences of personality, coping strategies, and social support," Preventive Medicine, vol.40, pp.46-53, (2005)

[3] C. H. Jones, "The spectrum of therapeutic influences and integrative health care Classifying health care practices by mode of therapeutic action," Journal of Alternative and Complementary Medicine, vol.11, pp.937-944, (2005)

[4] J. W. Henderson and R. J. Donatelle, "Complementary and alternative medicine use by women after completion of allopathic treatment for breast cancer," Alternative Therapies in Health and Medicine, vol.10, pp.52-57, (2004)

[5] C. Paterson and N. Britten, "Acupuncture as a complex intervention: A holistic model," Journal of Alternative and Complementary Medicine, vol.10, pp.791-801, (2004)

[6] Y. G. Song, "The development and effectiveness of mental health program using Chakra meditation for adults," M.S. thesis, NungIn University, (2017)

[7] M. D. Lee, "The effects of the physical and emotional activities the health, self perceived health status and the depression of the elderly," M.S. thesis, The Graduate School of Nursing GaChon University, (2012)

[8] S. L. Lim, "The development and effectiveness of mental health program using Chakra meditation for adults," Studies on Buddhist Art and Culture, vol.9, pp.311-331, (2017) 
[9] S. H. Kim, "A study on the development of Chakra activation yoga program and its effects - with a focus on the effect for relieving stress symptoms and response, negative automatic thinking and positive automatic thinking," Ph.D. dissertation, Seoul Buddhist Graduate School University, (2013)

[10] S. S. Doh, "The effects of a Chakra Mantra meditation program on the reduction of depression \& anxiety of middle-aged women," M.S. thesis, ChangWon National University, (2011)

[11] N. Y. Kim, "The influence of adult attachment of Korean adults on mental health and health behaviors', mediating role of relationship satisfaction," M.S. thesis, The NungIn University, (2018)

[12] Y. J. Ha, "The affect of Chakra meditation program on happiness of middle-aged women," M.S. thesis, International University of Korea, (2012)

[13] J. S. Kim, "The effects of the second Chakra harmony program on the sexual attitude," Ph.D. dissertation, personal relationship, and social support, ChangWon National University, (2009)

[14] K. Harinath, A. S. Malhotra, K.Pal, R. Prasad, R. Kumar, T. C. Kain, L. Ral, and R. C. Sawhney, "Effects of hatha yoga and omkar meditation on cardiorespiratory performance, psychologic profile, and melatonin secretion, The journal of alternative and complementary medicine ,vol.10, No, 2, pp.261-268, (2004)

[15] S. K. Devi, J. P. N. Chasauria, and K. N. Udupa, "Mental depression and kundalini yoga," Ancient Science of Life, vol.2, pp.112-118, (1986)

[16] H. J. Ha, "Influence of meditator's psychological characteristics on experiences of mindfulness meditation," M.S.thesis, Seoul National University, (2007)

[17] K. U. Kim, "A study on the effect of duration and motive for meditation on psychological well-being', M.S.thesis, The Graduate School of Seoul Cyber University Master's Thesis, (2016)

[18] K. I. Kim, J. H. Kim, and H. T. Won, "Korean manual of symptom checklist-90-revision, Seoul in press, Choung-Ang Juk-Sung Publishers, (1984)

[19] L. Derrogatis, R. Lipman and I. Covi, "The SCL-90: An outpatient psychiatric rating scale," Psychopharmacology Bulletin, (1973)

[20] H. C. Shin, C. H. Kim, B. L. Cho, J. W. Won, S. W. Song, Y. K. Park, Y. H. Yun and S. P. Chung, "Development of the Korean health status measure," Journal of the Korean Academy of Family Medicine, vol.23, pp.440-457, (2002)

[21] N. Y. Kim and S. L. Lim, "The effects of adult attachment on mental health and physical health behaviors," mediating effect of satisfaction of heterosexual relationship, Asia Life Sciences, in press, (2019)

[22] H. O. Kim and S. L. Lim, "The effect of negative life event on anxiety and depression in those who experienced meditation," Asia Life Sciences, in press, (2019)

[23] J. Y. Choi and K. H. Seo, "The effects of yoga practice on stress responses. Korean Journal of Clinical Psychology," vol.10, pp.455-473, (2005)

[24] T. Field, "Yoga clinical research review', Complementary the Rapies in Clinical Practice, vol.17, pp.1-8, (2011)

[25] L. Nathaniel, "Yoga for all', Nursing Times, vol.Jan, pp.52-54, (1984) 
Self-Exploration on Anxiety in Chakra Meditation Experienced People - The Mediation Effect of Emotional Health state Perception

This is empty by intention. 